\title{
THE SCOTTISH SOCIETY OF THE HISTORY OF MEDICINE
}

\author{
REPORT OF PROCEEDINGS \\ Session 1980-81
}

It is satisfactory to report that the Society completed another full programme for the session. Membership continues to increase steadily and admirable support was given to the meetings. The papers read were most acceptable and in the ensuing discussions time only was the limiting factor.

\section{THE THIRTY-SECOND ANNUAL GENERAL MEETING AND NINETY-SEVENTH ORDINARY MEETING}

The Thirty-Second Annual General Meeting was held in the Teaching and Research Unit of the Western General Hospital, Edinburgh, on 18 October 1980. The Ninety-Seventh Ordinary Meeting which immediately followed was addressed by Dr. Martin Eastwood, who spoke on:

\section{THE ROYAL COLLEGE OF PHYSICIANS LABORATORY: THE EXPERIMENT THAT BECAME ROUTINE}

From its inception the Royal College of Physicians of Edinburgh actively pursued an interest in the development of science, both medical and non-medical. In 1887, during the Presidency of Sir Douglas Maclagan (1812-1900) the College decided to establish a laboratory for the prosecution of original research. So came into being the first laboratory for medical research in Britain. It was opened at 7 Lauriston Lane, Edinburgh, with $£ 1,000$ capital outlay and $£ 650$ annual running costs. Dr. (later Sir) John Batty Tuke (1835-1913) was the first Curator and Dr. (later Sir) G. Sims Woodhead (1855-1921) the first Superintendent. Soon the laboratory was well used by some thirty research workers. The early work was devoted to bacteriology, pharmacology, anatomy, pathology, and even zoology.

Financial troubles dogged the laboratory almost from the beginning. Sponsors were necessary if the work was to continue. Arrangements were therefore entered into with the Carnegie Trust in 1903, and this association continued until 1950. It was also important that routine work be continued to be accepted, but payment now became necessary for this. Early eminent workers in the laboratory included James Dawson (1870-1927), distinguished for his work in neuropathology; and Diarmid Noël Paton (1859-1928), whose varied studies were of great significance in cardiology, metabolism, and particularly nutrition. The early years were also very productive in papers, 320 in all, while over 40,000 clinical reports, mostly bacteriological, were made.

During World War I, studies were undertaken on vaccines and sera, and there was 


\section{The Scottish Society of the History of Medicine}

considerable development of the work of the bacteriology department, particularly following the introduction of the Public Health (Venereal Diseases) Regulations, 1916.

Epidemiological studies were always a significant feature of the laboratory's work in bacteriology. Such studies included spirochaetosis, relapsing fever, tuberculosis, etc.

William Ogilvy Kermack (1898-1970) was appointed in charge of the chemical department of the laboratory in 1921. Three years later he was totally blinded in a laboratory accident. In spite of his great handicap he made major contributions to chemistry, epidemiology, mathematics, and chemotherapy, and in 1944 was elected a Fellow of the Royal Society. In 1948, he left the laboratory on his appointment as Professor of Biochemistry at Aberdeen University. Another distinguished research worker was Dr. Elizabeth K. Dawson, widow of James Dawson, and an eminent pathologist in her own right, who established our knowledge of carcinoma of the breast from the pre-malignant to the malignant phase. The head technician at the laboratory, William Watson, who died in 1947 at the age of seventy, worked there for fifty-four years.

During the last twenty years of its existence the laboratory work became more and more devoted to routine investigations. For example, during the period 1940-50 only seventy-three papers were published but 209,000 reports issued. The papers dealt with statistics, chemistry, pathology, and obstetrics.

With the advent of the National Health Service in 1948 and the development of a reorganised laboratory service, the future of the laboratory became uncertain. In 1950, the Carnegie Trustees terminated their financial arrangements to assist it. The building in Forrest Road, to which the laboratory had been transferred in 1896, was handed over to Edinburgh University and the laboratory as such, in effect, ceased to exist. So passed an institution so long established, so widely known and with so high a reputation. And now, sadly, forgotten!

\section{THE NINETY-EIGHTH ORDINARY MEETING}

The Ninety-Eighth Ordinary Meeting was held at the Department of Clinical Physics and Bio-Engineering, Glasgow, on 4 April 1981. Dr. Derek Dow, Archivist, Greater Glasgow Health Board, read a paper on:

\section{THE DISPENSARY OF THE ROYAL HOSPITAL FOR SICK CHILDREN, GLASGOW}

The movement to provide children's hospitals in Scotland followed the opening of London's Great Ormond Street Hospital for Sick Children in 1852. Edinburgh opened its doors in 1860 , and in 1861 it was proposed that a similar institution be erected in Glasgow. More than twenty years elapsed before this could be accomplished. The concept of a separate dispensary was mooted from the early $1870 \mathrm{~s}$, a departure from the pattern established in both Edinburgh and Aberdeen (opened in 1877). When the Glasgow Hospital for Sick Children finally opened in 1882, a deficit of $£ 6,000$ prevented the provision of a dispensary, regarded as an essential feeder for the wards. 


\section{Report of Proceedings 1980-81}

The necessary funds were raised by means of a Fancy Fair held in November 1884, and within a few weeks a site had been selected and purchased in West Graham Street. The location was well chosen, situated at the hub of the tramway network. The close proximity of the Glasgow Subway, opened in 1896, was an added bonus and greatly increased the effective catchment area of the dispensary.

After lengthy and heated exchanges between the Directors, the Ladies' Committee, and the President, Archibald Orr Ewing, the dispensary plans submitted by James Sellars, architect of the hospital, were finally adopted in 1887. Despite other heavy commitments, Sellars personally supervised the erection of the dispensary, which was opened on 1 October 1888. Only a week later, Sellars died of a gangrenous foot at the early age of forty-five.

The new dispensary maintained a separate identity, leading to occasional rifts with the parent body. Staffing always posed something of a problem, particularly during the two World Wars, when medical students and general practitioners were drafted in. Funding was rarely adequate, leading to long delays in obtaining necessary equipment. These difficulties were surmounted and a peak of 22,000 patients was reached in 1933.

Tabular representation of the dispensary work, using data from the annual reports, can provide a corrective to impressionistic or anecdotal history. Such studies highlight the changing pattern of dispensary work and its relationship with the hospital. Graphs have also permitted direct comparison with other hospitals such as Glasgow Royal Infirmary and the Royal Edinburgh Hospital for Sick Children. Close parallels with Edinburgh suggest the existence of fundamental changes in paediatrics in the twentieth century, with developments being less dependent upon individual practitioners than is frequently claimed in published histories.

The declining role of the dispensary can be traced from 1919, when ten per cent of all out-patients attended at the hospital proper. Proposals to close the dispensary were first voiced in 1937, but the Second World War offered a stay of execution. By 1949, the term "Dispensary" was replaced by the more prosaic "Out-Patient Department". The introduction of the National Health Service destroyed the dispensary ethos, as the family doctor became the first point of contact. The dispensary finally closed in January 1953 , having treated 785,189 patients in its sixty-four years of existence.

As a postscript to Dr. Dow's paper, it should be mentioned that the Department of Clinical Physics and Bio-Engineering occupies the premises of the former dispensary, after they had been suitably altered. On 8 November 1980, a magnificent new auditorium, built on the site of the dispensary's former waiting hall, was formally opened and named the James Nicoll Lecture Theatre. James Henderson Nicoll (1864-1921) was one of the most distinguished of the surgeons to serve on the staff of the dispensary. A symposium was held as part of the opening ceremony, and for this occasion Dr. Dow prepared an extended account of the dispensary and Nicoll's association with it. A brochure was printed and produced by the Department of Clinical Physics and Bio-Engineering.

An exhibition of documents relating to the dispensary, and of equipment illustrating the application of electricity to medicine and dating from around the time of Nicoll, was viewed by members following Dr. Dow's paper. 


\section{The Scottish Society of the History of Medicine}

\section{THE NINETY-NINTH ORDINARY MEETING}

This meeting was held on 13 June 1981, at Sunnyside Royal Hospital, Montrose, when two papers were presented. The first, by Dr. Kenneth M. G. Keddie, consultant psychiatrist at the Hospital, was entitled:

\section{STRAITJACKETS AND SECLUSION: MONTROSE ASYLUM, 1781-1834}

The first Bedlam, or house for the insane, in Scotland was built in 1703 in Edinburgh. There was little or no provision for pauper lunatics in Scotland until the establishment of the Montrose Asylum in 1781 by Mrs. Susan Carnegie. This asylum, combined as it was with an infirmary and dispensary, was granted a Royal Charter in 1810. In establishing the asylum, Mrs. Carnegie (1744-1821) had been influenced by several factors, of which two may be mentioned. The first was the death of the young Robert Fergusson (1750-74), a fellow poet, in the Edinburgh Bedlam. Dr. Andrew Duncan, senior (1744-1822), had visited Fergusson, and as a consequence had launched an appeal to establish a lunatic asylum in the city. It was not until 1809 , however, that the foundation stone of what was to become the Royal Edinburgh Hospital was laid. The second factor was Mrs. Carnegie's witnessing the plight of the mentally ill who were often chained to the wall, alongside criminals and vagrants, in the Montrose Tolbooth which stood in the middle of the High Street.

Mrs. Carnegie set the tone for the future development of the asylum. Originally the medical services for the patients were provided by local doctors, but this proving unsatisfactory, she recommended to the Managers the appointment on a yearly basis of an attending physician or surgeon at a fixed salary. This was finally agreed upon. Reports by the Forfarshire Sheriffs, visiting the asylum under legislation for the licensing and inspection of madhouses (1815), were consistently favourable, but that there was room for improvement was undoubted. Mrs. Carnegie insisted that there be appointed a resident medical superintendent. In 1834, thirteen years after her death, Dr. W. A. F. Browne (1805-85) was appointed the first superintendent.

Browne was a great innovator and had been much influenced by his tour of the Paris asylums. There he would have seen the changes inaugurated by Philippe Pinel (1745-1826), whose traditional unchaining of the lunatics at the Bicêtre took place in 1793. It was Browne who recommended the separation of the asylum from the infirmary and dispensary, an event accomplished in 1839.

At the present Sunnyside Royal Hospital, completed in 1858 and given the name it bears today in 1962, there exist many records from the early days of the asylum. The earliest administrative record dates from 1797, and the earliest clinical records are held in an "1818 Register of Lunatics". This was the year when details of patients were first kept at Montrose. This register gives a fascinating account of the types of restraint and the various forms of "medical cures" that were commonly in use at the time. Thus we read much of venesection, depletion, blistering, warm and cold baths, dietary modifications, and the use of opiates, cathartics, and emetics, forms of therapy applied to all types of illness, both mental and physical.

Dr. Allan S. Presly, principal psychologist, Tayside Health Board, then read a paper entitled: 


\section{Report of Proceedings 1980-81}

\section{FROM INSANITY TO MENTAL ILLNESS: \\ DOES HISTORY REPEAT ITSELF?}

At least four models of provision can be distinguished in the history of the care of the insane: (1) what would now be called a community care model, where no special institutions exist for the care of the insane but where there are forms of assistance in the community for the sufferer and his family; (2) what would now be called a district general hospital model, where the insane or mentally ill are provided for as an integral part of the general hospital system; (3) the special institution model where the insane or mentally ill are regarded as in some way different from other types of patients and require separate institutional provision; and (4) "boarding-out" or "half-way" systems where the insane are given over to the care and supervision of designated individuals.

At the time of the foundation of the Montrose Asylum, Infirmary and Dispensary, all four models had previously existed in Britain. Montrose opted for the general hospital model, and Mrs. Carnegie's hope was that "by good treatment and medical aid, some of these unfortunates might be restored to society."

The early nineteenth-century records at Montrose illustrate the prevailing view of insanity as a disease of the brain, and the methods used to treat it were translated from general medicine. As the century progressed, the limitations of these methods were gradually recognized, and while the search continued for new physical treatments, the influence of social and psychological factors on insanity were more widely acknowledged in the form of "moral treatment" which involved early removal from malign influences at home, good food, abundant exercise, and hard work. The asylum regime thus became in the late nineteenth century the main therapeutic agent.

The present century saw the gradual re-establishment of medicine in the treatment of the mentally ill, with the discovery of malarial treatment for general paralysis of the insane, and the introduction of narcosis, insulin coma therapy, ECT, psychosurgery, and the major tranquillizers and anti-depressants.

The establishment of the National Health Service re-integrated the psychiatric hospitals with the other medical services from which they had become alienated, leading eventually to the case being made again in the 1960s for the psychiatric services to be based on the general district hospitals - not a new idea as Montrose's history illustrates, although Montrose abandoned the attempt in 1839.

Finally came the recognition that the asylum regime, so much favoured by the Victorians as a powerful therapeutic force, was very far from being so, and could in fact be highly detrimental to the patient's welfare. This led to the recent efforts to provide alternatives to asylums in the form of community care.

It may be concluded that Montrose Asylum's history, and examples from earlier times suggest that the questions facing us now as regards proper provision for the mentally ill are in many ways similar to those faced by our predecessors when Montrose Asylum was founded. Are psychiatric hospitals to be separated or integrated with the general hospitals? Can we have institutions without institutionalization? Would community care, given a fair chance, prove a better alternative? What is the correct balance between "medical" and "moral" treatment approaches? 


\section{The Scottish Society of the History of Medicine}

The history of the treatment of the insane continues to pose the same questions. Most of the solutions now being advocated have been tried before, and perhaps we need to learn from where things went wrong in the past.

Since 1981 marks the bicentenary of the foundation of the Montrose Asylum, Infirmary and Dispensary, a plaque was unveiled by Princess Alexandra at the site of the original hospital on 20 June 1981, and on 23 June, a museum, illustrating many aspects of the hospital's history, was opened by Lord Southesk, a descendant of Mrs. Susan Carnegie.

Sir Charles Illingworth, President

N. H. Gordon, Honorary Secretary

H. P. Tait, Editor, Report of Proceeding 